\title{
Indispensability and explanation: an overview and introduction
}

\author{
Daniele Molinini $^{1}$ - Fabrice Pataut ${ }^{2}$. \\ Andrea Sereni ${ }^{3}$
}

On November 19-20 2012, the Institut d'Histoire et de Philosophie des Sciences et des Techniques in Paris hosted a two-day workshop on Indispensability and Explanation organized by Marco Panza and Fabrice Pataut. Most of the papers presented on that occasion or, rather, their distant descendants, have been included in this special issue; some additional contributions came in at a later time. The workshop was structured so that a rejoinder followed the delivery of each paper and we have remained faithful to this structure for their publication even though some of the rejoinders have almost become stand-alone papers thanks to suggestions by our panel of reviewers, to whom we would like to express our gratitude for their invaluable work.

The aim of the workshop was to foster a discussion of disputes at the crossroad of two main topics in recent philosophy of mathematics and philosophy of science: the role of mathematical explanations in the natural sciences and the Enhanced Indispensability Argument for platonism. The main idea was to explore their links with other issues such as mathematical realism, inference to the best explanation, and the applicability of mathematics. A number of significant papers by Alan Baker, Mark Colyvan

$\triangle$ Daniele Molinini

dmolinini@gmail.com

Fabrice Pataut

Fabrice.Pataut@univ-paris1.fr

Andrea Sereni

andrea.sereni@iusspavia.it

1 Department of Philosophy, Communication and Media Studies, Roma Tre University, Via Ostiense 234, 00144 Rome, Italy

2 FRE Sciences, Normes, Décision, CNRS (Centre National de la Recherche Scientifique), Maison de la Recherche, 28, rue Serpente, 75006 Paris, France

3 NEtS Centre for Neurocognition, Epistemology and Theoretical Synthax, Institute of Advanced Studies of Pavia, IUSS, Piazza della Vittoria n.15, 27100 Pavia, Italy 
and Christopher Pincock indicate that the debate triggered by the Quine-Putnam challenge of the late sixties and early seventies has supplemented the discussion about the reliability of our beliefs about causally inert abstracta with a discussion of the role that mathematics, conceived as a body of theories about such abstracta, plays in the explanation and prediction of natural phenomena (Baker 2005; Colyvan 2001; Pincock 2012).

The point of the Paris workshop was to capture the content and scope of the renewal of these traditional debates in the wake of that shift. To our knowledge, a discussion of these interconnected topics in the form of a special issue was still missing from major philosophical journals. We are therefore all the more grateful to Marco Panza for his support in this project and to editors-in-chief of Synthese, Otávio Bueno, Wiebe van der Hoek and Gila Sher, for having warmly welcomed our proposal. Many thanks are due in particular to Otávio Bueno for his help and patience in its completion.

Although the essays collected in this issue will be of interest to anyone involved in these debates, it seems to us that they also offer a fairly comprehensive introduction to some of the most discussed questions for those willing to familiarize themselves with this part of contemporary philosophy of mathematics. In this Introduction, we want to address both audiences by rehearsing the historical and conceptual essentials of the background literature and by placing the essays that follow in their proper connection with some major threads in the debate.

\section{The indispensability argument}

Let semantic realism be the claim that mathematical statements are true independently of what makes them true, and platonism be the claim that mathematical objects exist. Semantic antirealists deny the former, nominalists deny the latter. Usually, although it needs not be so, these claims bear upon, respectively, the theorems of well-established, fruitful and consistent mathematical theories, and the objects that the terms occurring in these theorems denote when read at face value. There are many ways in which philosophers may try, and have indeed tried, to argue for both claims. All are hostage to a well-known epistemological problem. Mathematical objects, if they exist, are generally thought to be abstract, i.e. non spatial, non temporal and non causal (and, possibly, necessarily existent), inhabiting a realm which is both objective and disjoint from the concrete world humans live in.

How are we supposed to gain knowledge of these objects, and of truths about them if, by their very nature, they defy our most reliable, causally-based methods of securing epistemic access to the objects that surround us? And if no direct epistemic access to them may be granted, what warrants our beliefs in statements about them? This concern was well-known to Plato and Aristotle and has received more explicit formulations in the late nineteenth century. In the twentieth century, Paul Benacerraf has voiced it in a now famous and clear-cut way (Benacerraf 1973).

The assumption that our knowledge of objects may proceed only via causal connections is, of course, questionable. Philosophers of rationalist inclinations have proposed various alternative ways of securing access to abstract mathematical objects, either by positing some special faculty of mathematical intuition (Gödel 1947, 1964; Parsons 
1979-1980) or, perhaps less controversially, by explaining how it can be granted through rational reflection, possibly together with principles concerning language and semantics, as in Frege's original logicist project (Frege 1884) and the neo-logicist project of Hale and Wright (2001), or again as in Shapiro's ante rem structuralism (Shapiro 1997).

If we assume a broadly empiricist background, or somehow maintain that mathematical knowledge cannot be based on knowledge of facts involving abstract mathematical objects, a few routes seem to be open. (i) We can bite the bullet and claim that mathematical statements, when taken at face value, are false insofar as they are about abstract objects that do not exist, or that they are, at best, fictionally true. As far as applied mathematics goes, this may either involve claiming that scientific theories can be rephrased in purely nominalistic terms (Field 1980) or that, even if those theories cannot be so rephrased, the mathematical language they employ does not commit us to the existence of mathematical objects (Melia 2000; Yablo 2001, 2005; Azzouni 2004). Colyvan has labeled these the "hard road" and the "easy road" to nominalism, respectively (Colyvan 2010; see also Colyvan 2012 and the essays by Jody Azzouni, Otávio Bueno, Mary Leng, David Liggins, Stephen Yablo in the same issue of Mind). (ii) We can paraphrase purely mathematical statements and claim that their genuine logical form is betrayed by their grammatical structure so that, when properly understood, they forthrightly display their not being about mathematical objects at all (Chihara 1991). (iii) We can claim that at least some mathematical objects are, as a matter of fact, concrete objects (Mill 1843; Maddy 1990). (iv) We can argue that, despite appearances, the subject matter of mathematics is not individual mathematical objects but the structures that certain systems of objects instantiate, i.e. the set of relations between them, and then claim that knowledge of these structures is less controversial than knowledge of abstract objects (Hellman 1989); we may also, with Shapiro, claim that these structures are abstract objects in their own right, but this will again require warranting our access to abstract objects (Shapiro 1997).

At a closer look, another route is still open. Even though we cannot acknowledge direct access to mathematical abstract objects, it might be enough if we can show that knowledge of the truth of mathematical statements (and of the abstract objects they are about) can somehow be traced back, even indirectly, to knowledge of the truth of empirical statements (and of the concrete objects they are about). The strength of the so-called "indispensability argument" is that it offers exactly such a route to mathematical knowledge, a route whose initial assumptions are acceptable by platonists and nominalists alike, but whose conclusion would be at least semantic realism and, possibly, platonism.

Suppose that some scientific theories are true or well-confirmed, or that we are justified in taking them to be so, and suppose furthermore that these theories appeal in some indispensable way to mathematical theories which are purportedly about mathematical objects in such a way that they could not be true if the latter were not also true. It follows that such mathematical theories are themselves true or wellconfirmed, or that we are justified in taking them to be so. If we also suppose that these theories are true only if the mathematical objects they are purportedly about exist, it follows that these objects exist, or that we are justified in taking them to exist. 
This apparently simple thought can be sharpened in different ways leading to distinct arguments; moreover, the thought conceals a large number of philosophical intricacies due to its close ties with other central issues in the philosophy of science, among which naturalism, scientific realism and confirmational holism, as well as with concerns about the proper characterization of the very notion of indispensability (for a general discussion, see Colyvan 2001 and Panza and Sereni 2013, Chs. 6-7).

Although distant ancestors of indispensability arguments may be found in Frege (1893-1903, Vol. II, §91; see also Garavaso 2005 and Sereni 2015) and in Gödel (1947, 1964), the first substantial suggestions are to be found in Quine (1948, 1951, 1966, 1969, 1981), while a first explicit formulation is to be found in Putnam (1971). The contemporary debate on the indispensability argument has two major loci. On the one hand, Field has suggested that the indispensability argument is the only plausible argument for mathematical platonism, and has proposed a nominalist programme to defeat it (Field 1980, 1989), suggesting, e.g., that Newtonian gravitational theory be rewritten without any appeal to reals. Colyvan (2001), on the other hand, offers the more sustained defence of the argument available so far, thus accounting for various recent discussions (among which, beyond Field's, those in Maddy 1992; Sober 1993 and Resnick 1995). As far as we are concerned here, Field and Colyvan hold a special place. Field is the first to have established a connection between the indispensability argument and the notion of explanation, whereas Colyvan has provided what is today often referred to as the standard formulation of the indispensability argument, although many others have been offered. Still more relevant to our purposes is a further twist in the debate, due to Baker (2005, 2009), who has given the notion of explanation centre stage in the debate on indispensability.

Field first suggested that at least one version of the indispensability argument could be stated in terms of indispensability "for explanations," in such a way that an appeal to mathematical theories in what is believed to be the best explanation of a range of empirical phenomena gives us "a strong reason to believe" in the truth of these theories and, consequently, in the existence of their objects (Field 1989, pp. 14-15). But it is with Baker's so-called Enhanced Indispensability Argument that the notion of mathematical explanation comes to the fore in the recent debate. Baker remarks that it is not enough, in order to commit oneself to the existence of mathematical objects that the theories and statements about them be indispensable in the natural sciences: they must be indispensable in the right way, e.g. they must themselves offer the best explanation of some empirical phenomena (Baker 2009).

The basic idea behind the argument must accordingly be modified as follows. If some scientific theories are true or well-confirmed, or if we are justified in taken them to be so, and they appeal to mathematical theories (which are purportedly about mathematical objects) that play an indispensable explanatory role, then these theories are themselves true or well-confirmed, or we are justified in taking them to be so; and if they can be true only if the mathematical objects they are purportedly about exist, it follows that these objects exist, or that we are justified in taking them to exist.

Various examples have been discussed in the recent literature. The most famous one is provided by Baker and involves the explanation of the ethological fact that Magicicadas populating some regions of North America have life cycles of either 13 or 17 years (Baker 2005). Why do Magicicadas have life cycles of a prime number 
of years? The most credited explanation involves not only some environmental conditions, e.g. that in a particular region the cicadas are constrained by environmental factors to a life cycle between 12 and 15 years, and by evolutional constraints, i.e. that survival of the species is favoured when life cycles minimize intersection with the life cycles of, among others, predator species; but it also involves a mathematical theorem about prime numbers to the effect that prime life cycles minimize the relevant intersection as opposed to non-prime life-cycles. Other recurring examples include an explanation of why bees build hexagonal honeycombs, where a geometrical theorem on how to divide an area in equal parts with the minimum overall perimeter gives the required explanation, together with ecological and evolutionary constraints (Lyon and Colyvan 2008); or the explanation of why it is impossible to walk from an initial point back to the same point by crossing each of Königsberg's seven bridges only once, where a theorem in graph theory gives the required explanation of how such a physical path cannot exist (Pincock 2007b). These and other cases are discussed in the papers of the special issue. What matters for now is that, thanks to the Enhanced Indispensability Argument, the notions of explanation and indispensability end up being intrinsically connected, at least as far as this branch of the debate on mathematical truth and existence is concerned.

But what supports the argument's conclusion? In its previous versions, following Field (1989), one could reckon at least two ways of understanding indispensability: mathematics can be theoretically indispensable insofar as one must resort to mathematics to state a given scientific theory, or it can be deductively indispensable insofar as it may be useful to deduce non-mathematical statements from non-mathematical axioms. In both cases, one could have a more or less clear clue as to why indispensability entails both truth and existence. But why should the indispensable explanatory role of some theory or some object warrant belief in the truth of the former or the existence of the latter?

Hidden, as it were, behind the Enhanced Indispensability Argument, there seems to be an endorsement of the principle of inference to the best explanation, according to which when presented with a number of rival and well-pondered explanations of some given phenomena, we are rationally entitled to believe in the literal truth of the best explanation among those, even when such truth implies the existence of entities to which we can have no direct observational access. Inference to the best explanation is widely used in philosophy of science, chiefly by those scientific realists who believe scientific theories provide literally true, although approximate, descriptions of the physical world, even in its unobservable parts. The principle is what warrants belief in the existence of unobservable physical entities, i.e. entities the positing of which allows for the best explanation of observable phenomena. While some versions of the indispensability argument can be presented in the form of deductive arguments, its enhanced version seems to appeal crucially to an abductive principle like inference to the best explanation, which, needless to say, is highly controversial and has elicited much criticism (for a general discussion, see van Fraassen 1980 and Lipton 2004).

The papers of the special issue discuss how a properly formulated indispensability argument may be based on considerations of explanatory power pertaining to the relevant segments of mathematics (typically, of pure mathematics that happens to be applied), how mathematical theories (provided they are about abstract mathemati- 
cal objects) may offer explanations of empirical phenomena, and how (and indeed whether) inference to the best explanation may be accepted as a reliable principle when the existence of abstract mathematical objects is at stake. Before guiding the reader through the content of the papers, it will therefore be helpful to ponder some more on the cognate notions of explanation and inference to the best explanation.

\section{Mathematical explanation}

The expression "mathematical explanation" is generally used to refer to two distinct classes of explanations: mathematical explanations in science and mathematical explanations in mathematics. In both cases, mathematics is regarded as playing an essential role in the explanation provided, in the sense that mathematics unveils the reason why a particular empirical or mathematical state of affairs obtains, although they denote different things: the former are explanations in the empirical sciences that make use of mathematics, whereas the latter refer to explanatory practices that take place within the realm of mathematics itself.

As Paolo Mancosu points out, the topic of mathematical explanation in science has a long and rich history that can be traced back to Greek philosophy (Mancosu 2008, 2011; Mancosu and Pincock 2012). Aristotle was indeed the first to acknowledge the existence of such explanations and to provide an account of them. In his Posterior Analytics I.13, Aristotle draws a distinction between demonstrations "of the fact," which he deems not explanatory, and demonstrations "of the reasoned fact," which are explanatory because they capture the causal structure of the world. This distinction, together with the relation of subordination between mixed sciences such as optics or harmonics, and areas of pure mathematics, allows him to claim that there are mathematical explanations of physical phenomena.

Aristotle's considerations advanced in the Posterior Analytics were very influential until the sixteenth and seventeenth centuries and undoubtedly provide us with the very first account of mathematical explanation in science. Nevertheless, as the scientific enterprise moved forward and mathematics was progressively embedded in the empirical sciences, Aristotle's picture of explanation was subject to modifications and criticisms, to the point of being replaced by entirely new conceptions of how mathematics plays an explanatory role in the natural sciences. For instance, the explanatory role that Aristotle attributed to mathematics was challenged in the Quaestio de Certitudine Mathematicarum, an important philosophical debate that took place during the Renaissance, while the mathematization of nature carried out by Newton imposed a new standard for explanation during the eighteenth century. Moving to more recent times, the close interplay that took place between mathematics and the empirical sciences resulted in a very complex scenario, in which the boundary between mathematics and the mathematized has become evanescent, prompting philosophical analyses of explanation quite different from that advanced by Aristotle in his Posterior Analytics.

What about the twenty-first century? In the era of logical empiricism, the notion of mathematical explanation in science was largely ignored, and philosophers were mainly interested in scientific explanation. This lack of consideration is well mirrored in the Hempelian picture of scientific explanation, in which laws of nature and initial 
conditions of an empirical nature are paramount in explanations, while mathematics has no explanatory import. Nevertheless, a renewed interest on the topic arose at the end of the seventies with two seminal papers by Mark Steiner: "Mathematical explanation" and "Mathematics, explanation and scientific knowledge" (Steiner 1978a,b, respectively). These papers are the first explicit contributions to the study of the nature of mathematical explanation in analytic philosophy; with his original account of mathematical explanations in science and in mathematics, Steiner gave a fresh spin to the philosophical discussion.

Since Steiner's 1978 articles, interest in the topic has been continuously growing. Many philosophers have looked for an original account of how mathematics may provide explanations in science (Baker 2005; Pincock 2007a; Batterman 2010; Molinini 2011; Friend and Molinini 2015), and have tested traditional accounts of scientific explanation in the context of mathematical explanation (Sandborg 1998; Hafner and Mancosu 2008; Molinini 2014). Although some philosophers have challenged the idea that mathematics may have an explanatory import in science (Melia 2000; Daly and Langford 2009; Saatsi 2011), the very existence of mathematical explanations in science is now largely acknowledged and its study is central to the agenda of contemporary philosophers of mathematics and science. This is also due to the fact that the issue is central to a number of philosophical debates, three of which deserve a particular attention insofar as they are explored in most of the contributions to this special issue.

The first concerns the applicability of mathematics to the natural and social sciences. As noted by Shapiro, in order to give an account of mathematical explanation in science we should first give an account of how mathematics successfully applies to the world: "Strictly speaking, a mathematical description, model, structure, theory, or whatever, cannot serve as an explanation of a non-mathematical event without an account of the relationship between mathematics per se and scientific reality per se" (Shapiro 1983 , p. 525). This is why some philosophers engaged in the debate on mathematical explanation have turned their attention to the notion of applicability and proposed their own model of the applicability of mathematics (Pincock 2004, 2007a, 2012; Bueno and Colyvan 2011).

A second debate in which the notion of mathematical explanation in science is now extensively discussed is that which relates to the use of mathematical and physical idealizations in science. Idealizations used in scientific theorizing are, strictly speaking, false. Nevertheless, they do a terrific job and we successfully use them in science. If a mathematical explanation makes an essential use of such idealizations, then we should explain how these idealizations, which are literally false in the sense that they do not accurately describe the world, nevertheless can have a role in such explanations (Pincock 2007b, 2012; Batterman 2010; Bueno and French 2012).

A third debate concerns semantic realism, and platonism about mathematics via the Enhanced Indispensability Argument, as we discussed in the previous section.

Explanation-based versions of the indispensability argument do not just appeal to the notion of explanation: they appeal to the fact that some explanations are better than others and that a best mathematical explanation of some phenomenon may be selected. They rely, in other words, on the controversial principle of inference to the best explanation. 


\section{Inference to the best explanation}

The inference to the best explanation principle is a crucial ingredient of the Enhanced Indispensability Argument, so it should come as no surprise that analyses of the argument focus on issues related to it. A crucial question in this respect is: what is a best explanation (of some physical phenomenon)? In order to answer this question, not only do we need to determine when the mathematical treatment of an empirical phenomenon is genuinely explanatory, but we also need a criterion to rank mathematical explanations of empirical phenomena according to their degree of explanatoriness. Such a measurement would allow us to judge whether some explanations fare better than others in terms of explanatory power, and to apply the contentious principle whenever we are confronted with equivalent but competing explanations, i.e. equally explanatory mathematical treatments of the very same natural phenomena that contrast in terms of their commitment to mathematical objects. Although these issues are central to the Enhanced Indispensability Argument, research on these topics has only just begun (Lyon 2011; Baker 2012; Pincock 2014). Much of the recent discussion on the argument has focused on specific case studies in which, according to their defenders, evidence from scientific practice indicates that mathematics does indeed play a genuine explanatory role (Baker 2005, 2009; Baker and Colyvan 2011). However, no general condition that a mathematical object must satisfy in order to play a genuine explanatory role has yet been offered, thus making life easier for anyone keen on blocking the Enhanced Indispensability Argument based on an inference to the best explanation (see Daly and Langford 2009; Saatsi 2011).

On a finer grained level, a clarification of the notion of indispensable explanatory role played by mathematical objects, a notion which appears in the premises of the argument first formulated by Alan Baker, is needed. What does it mean for a mathematical object, or a set of mathematical objects, to play an indispensable explanatory role in science? Are there kinds of explanations whose mathematical posits we can dispense with, either nominalistically or otherwise, while possibly retaining the explanations' original explanatory power; or are there cases where mathematics (albeit not any particular mathematical object as such) proves to be indispensable to the overall explanation? Although these questions have been partially addressed in the literature (Melia 2000, 2002; Colyvan 2001, 2002; Baker 2009; Rizza 2011), we are still far from a comprehensive examination of these points.

Another crucial issue is the extent to which concerns about inference to the best explanation that have been raised in the context of scientific realism also apply in the case of the Enhanced Indispensability Argument. Many scientific realists usually resort to a causal criterion when arguing in favour of their commitment to physical unobservables (see Cartwright 1983; Hacking 1983; Salmon 1984; Giere 1988), thus placing a causal constraint on such inferences that, clearly, may not be satisfied in the context of mathematical explanations. The application of the principle to physical unobservables may therefore differ substantially from its application to abstract mathematical entities (see Leng 2005; Bangu 2008, 2013; Pincock 2012). These considerations prompt interpretative issues concerning the inferential strategy at the core of the Enhanced Indispensability Argument: may we, or may we not resort to versions of inferences to the best explanation that do not rely on a causal notion of explanation? 
What sorts of restrictions may the platonist apply to the principle in order to defend the enhanced version of the indispensability argument from the various criticisms that have been levelled against it, and how would this affect it? How are various forms of inferences to the best explanation related to the Enhanced Indispensability Argument? Are there non-causal strategies that might be used in such arguments that do not rely on such inferences?

\section{The essays}

The papers collected in this special issue are all concerned with debates that have been, however sketchily, touched upon in the previous sections.

The first four papers, by Alan Baker, Fabrice Pataut, Sam Baron, and Silvia De Bianchi, address questions concerned with the explanatory force of indispensability considerations, especially when explanations in the concrete realm are compared with mathematical explanations.

The following four papers, by Daniele Molinini, Andrea Sereni, Jacob Busch and Joe Morrison, and Joshua Hunt, focus on the role of inference to the best explanation in the Enhanced Indispensability Argument, with a special interest for the vexed question of how to decide between equivalent and incompatible explanations.

The last set of four papers, by Marco Panza and Andrea Sereni, Henri Galinon, David Liggins, and Matteo Plebani, tackle the debate on the Enhanced Indispensability Argument, and on indispensability arguments generally, discussing what conditions must be satisfied in order for an indispensability argument to be compelling, especially when based on considerations of explanatory power, and how such arguments relate to other notions of explanation in metaphysics, such as grounding.

Alan Baker's "Parsimony and inference to the best mathematical explanation" considers cases where the strengthening of the mathematical results that play a role in the platonistic explanations of natural phenomena helps reduce their concrete commitments. Should parsimony with respect to concreta be preferred to parsimony with respect to abstracta in optimization explanations? Baker argues that it should when optimization explanations involving stronger mathematical results avoid the postulation of dubious non observed concreta (e.g. kinds of predators of magicicadas for which there is no direct empirical evidence in Baker's famous example from Baker 2005). If it is claimed that parsimony with respect to mathematical objects must still prevail, the nominalist will be playing for (very) high stakes indeed for she must now provide explanations that replace or paraphrase more mathematics, given that the stronger applied mathematics, just like the weaker one without the inflation of abstracta, is to be taken at syntactic and semantic face value in the so-called "hard road" approach to nominalismin Colvyvan's phrase- that Baker rejoins to here. This increment in labour may cast doubt on the feasibility of nominalizations. It has often been asked, and an important part of Baker's contribution to this volume discusses this issue, whether proofs of applied mathematical results contribute to the platonistic force of explanations. 
In "Comments on 'Parsimony and inference to the best mathematical explanation"," Fabrice Pataut objects that if proofs must play a theoretical role in explanations that are able to answer why-type questions - say why prime periods are uniquely optimal in Baker's Magicicada case-it is nevertheless impossible to fix a principled limit to the additional mathematical apparatus one might have to appeal to in the carrying out of such proofs. Moreover, proofs, in this approach, must be construed as formal derivations — since the anti-platonist's task, after all, is to nominalize them-and it is unclear how derivations could contribute to the platonistic force of any explanation, say by playing a "strong role" in Tallant's sense of being an integral part of an explanation, e.g. one yielding a beneficial trade-off between more abstracta and less concreta. Notice, in this respect, that the very same kind of questions might be asked, mutatis mutandis, about the substantiations of the non-mathematical means that a nominalistic explanation might resort to, whether it be of a mereological kind (Tallant 2013), or of an axiomatic kind (Rizza 2011): how do such substantiations contribute to the (nominalistic) force of non-mathematical explanations of natural phenomena? A clear conception of the relation between nominalistic paraphrase and explanatory force is needed if any enhanced indispensability argument is to be countered.

Another approach to the relation between indispensability claims and explanatory force is proposed by Sam Baron. In "The explanatory dispensability of idealizations," Baron argues that idealizations pose a threat to the Enhanced Indispensability Argument: although idealizations improve explanatory force, we wouldn't countenance them in the way a platonist countenances the mathematical objects of platonistic explanations. In particular, Baron proposes an explanation of how it is that mathematics might carry the explanatory load and that mathematical objects might play a theoretical role (whereas idealizations, as claims whose falsity is known, may not do either) in terms of difference-making and counterfactuals. Mathematical results involving probability distributions are central to the Lévy walk optimality model of random walks of organisms searching for food. Baron's strategy is to break the difference between the mathematics resorted to in that model and the idealization of, say, memory capacity, on the ground that the features which are the target of the idealization do not make a difference to the natural phenomenon being explained, whereas mathematical objects might make a difference. The crucial point here is that by pulling idealizations and mathematics apart with regard to their status in scientific explanations, the antirealist attitude toward idealization leaves the road open for some form of realism with respect to mathematics.

Silvia de Bianchi objects that the distinction between mathematical existence claims and idealizations needs a more compelling criterion than the one provided by Baron, namely a criterion which will explain how mathematical objects are relevant, i.e. make a difference, in non-causal terms, with respect to the phenomena which are the target of the explanation, when idealizations, admittedly, are not relevant in that sense. The main point of her "Which explanatory role for mathematics in scientific models? Reply to "The explanatory dispensability of idealizations"' is to stress that the assumptions of idealizations resort to mathematics in order to be expressed so that, after all, idealizations (of, say, memory, in the Lévy walk case) contribute to the fact that mathematics carries the explanatory load in a given model. When one contrasts the platonistic force of a mathematical explanation with, on the one hand, the nomi- 
nalistic parsimony of a non-mathematical one and, on the other, the counterfactual and difference-making analysis provided by Baron, it is striking how much the analysis of the notion of explanatory load lies at the core of the issue of the Enhanced Indispensability Argument. After all, it should be clear in the first two cases, which features of the role of an explanans, be it mathematical or, say mereological, is responsible for the explanatory load. As for the idealization case, the divorce of explanatory power from explanatory load must rely on the idea that explanatory models yield the relevant explananda without the idealizations carrying the explanatory load in these models. The debate on these questions remains open.

In "Evidence, explanation and enhanced indispensability," Daniele Molinini bases his criticism of the Enhanced Indispensability Argument on an analysis of some of its core notions. He proposes an original account of mathematical explanation in science and discusses the consequences of the proposal in the general context of the argument. An explicit and formal definition of indispensability is provided, along with an argument to the effect that the resulting reading of the Enhanced Indispensability Argument corresponds to the one endorsed by platonists such as Alan Baker and Mark Colyvan. Molinini nevertheless argues that once we consider specific case studies of equivalent though competing explanations, the principle does not apply and Baker's Enhanced Indispensability Argument is in danger. Molinini discusses various strategies that the mathematical realist who argues along the enhanced indispensability line may adopt to answer the criticism, one of the main points being that the advocate of indispensability needs an additional criterion to rate mathematical explanations in science and justify the use of the principle resorted to in the indispensability argument. In the conclusive section of his paper, Molinini proposes that we adopt a pluralist view of mathematical explanation, a view that provides an account of the genuine character of mathematical explanations in science. However, should this route be followed, the notion of the explanatory power of mathematics would lose its ontological import and, pace platonists, could not be used in the Enhanced Indispensability Argument.

Andrea Sereni examines these proposals and criticisms in "Equivalent explanations and mathematical realism" while providing a general discussion, both of the problem of equivalent but competing explanations, and of the strategies that may be adopted with respect to the Enhanced Indispensability Argument. Sereni fears that Molinini's attack on the argument may lack generality and argues that it should be buttressed if the platonist, starting from indispensability, is to be refuted. His assessment of one of Molinini's case study suggests that the evidence recovered from scientific practice casts doubt, both on the equivalence of the competing explanations considered and on the fact that two different explanations of the same physical phenomenon are really at stake. Sereni then objects that Molinini's pluralistic proposal may fail to evaluate the advantages of explanations across different contexts. A form of relativism lurks in the background, which seems to go against our intuitions about what a better explanation amounts to. In the last section of the paper, Sereni reviews various inferential moves, either based or not on inferences to the best explanation, that may be made when genuinely equivalent explanations are available, moves that would allow the platonist to resort to the notion of mathematical explanation as a crucial ingredient of her ontological commitment to abstract objects. 
Jacob Busch and Joe Morrison's "Should scientific realists be platonists?" offers a detailed analysis of the inferential strategy used in the Enhanced Indispensability Argument. The authors devote particular attention to what they call the "parity" premise employed in the argument. According to that premise, mathematical realists may rely on some inference to the best explanation, just as scientific realists do, i.e. using the very same epistemic or inferential resources. It seems that this premise is widely assumed by platonists who endorse the Enhanced Indispensability Argument. However, if parity is false, contrary to what has been claimed by some platonists, scientific realists are not committed to the existence of mathematical entities via such an inference. Busch and Morrison believe parity is false, in particular because scientific realists invoke a causal model of explanation to ground their ontological commitments. Furthermore, scientific realists resort to a variety of inferences to the best explanation, say in order to settle underdetermination problems, or to defend the reliability of scientific methodology in building approximately true theories. The pressure is thus very high on platonists and it remains unclear in this respect how the parity requirement may be imposed on the Enhanced Indispensability Argument: it is thus up to the platonist to shed light on how and when mathematics yields explanatory power.

Joshua Hunt's reply in "Indispensability and the problem of compatible explanations" gives a new twist to the problem of equivalent but competing explanations and provides a general argument to block the Enhanced Indispensability Argument. His argument relies on a distinction between mathematical and physical entities based on the notion of ontological competition. Two physical entities compete in a strong sense when they are logically contradictory; they compete in a weak sense when they undermine the probable existence of each other. Hunt claims that while physical unobservables may compete with one another, mathematical entities cannot. As far as the Enhanced Indispensability Argument is concerned, in the case of equivalent but competing explanations, the lack of competition prevents an inference to the best explanation from establishing the indispensability of particular mathematical objects. Additionally, and similarly to what Molinini claims in his own paper, Hunt maintains that an inference to the best explanation fails to distinguish between equivalent but competing explanations and therefore cannot establish that one particular mathematical explanation is indispensable. Finally, Hunt offers a discussion of how the adoption of an ante rem structural standpoint would save the platonist from his objections, although such a realist stance should be motivated independently from the Enhanced Indispensability Argument.

Marco Panza and Andrea Sereni, in "The varieties of indispensability arguments," investigate under which conditions an indispensability argument, once properly formalized, can be (non-circularly) sound. The authors trace most current versions back to a general argument schema, to be specified by appropriate instances of several parameters. Full specification of all parameters lead to genuine indispensability arguments, and only these should be assessed as either sound or unsound. A strengthened version of indispensability arguments is identified, in connection with the appeal to naturalism: strengthened arguments not only support the thesis that the objects of some indispensable mathematical theory meet a given condition $A$ if they are appropriately indispensable to some suitably characterized scientific theories, but also that no other object meets that condition. The notion of indispensability discloses its relational char- 
acter by also being specifiable according to various parameters. Depending on how condition $A$, i.e. the property possessed by the relevant scientific theories (different properties leading to what authors call "ontological" or "epistemic" arguments) and indispensability are specified (together with other parameters), one could get different genuine indispensability arguments (possibly leading to what the authors label "platonism," "veridicalism" and "externality"). Versions of the Enhanced Indispensability Argument enter stage once the notion of indispensability is specified according to explanatory power. Panza and Sereni suggest that the currently available versions of such arguments rest on controversial or question-begging assumptions. By considering specific cases of alleged indispensability (involving arithmetic, real analysis and set theory) for either single (mathematical and scientific) theories, or families of theories, they conclude that no evidence for a sound argument seems available or easily forthcoming.

In "Naturalizing indispensability," Henri Galinon points out that Panza and Sereni characterize the notion of indispensability as non-transitive, arguing that this conflicts with the widespread use of impure methods in science. When the epistemic role of interpretation functions is considered, this may also affect some of the claims advanced by Panza and Sereni to the effect that, in particular instances, neither set theory nor any other mathematical theory that can be reinterpreted in it will be indispensable to a given scientific theory for some particular task. Moreover, in other simpler cases involving finitary arithmetic, practical limitations (concerning phenomena known as "speed up results") indicate that the epistemic role of an appeal to numbers cannot be obviated by nominalistic means. More generally, practical and epistemic considerations suggest that a less strict logic of indispensability may be needed. As regards explanatory indispensability, Galinon endorses a naturalist attitude: he suggests that the empirical question whether the scientific community does as a matter of fact appeal to mathematics as a genuine explanatory ingredient in explanations should replace the normative question whether and how it is possible for it to play that role. A statistical analysis through queries in journal titles and papers shows that mathematically-driven explanations are widely endorsed in many scientific accounts. This naturalistic path would allow discussing the explanatory power of mathematics in science without assuming anything about the semantics and epistemology of mathematics, thus leaving room for a non-question-begging justification of the explanatory indispensability of mathematics.

In "Grounding and the indispensability argument," David Liggins advances a novel strategy for resisting indispensability arguments by appealing to the notion of grounding. When offering an indispensability argument based on the allegedly mathematical explanation of physical facts, platonists appeal to relations holding between physical and mathematical objects: according to Liggins, nominalists can give an equally good explanation by appealing to the nominalistic fact in virtue of which this relation is meant to obtain (e.g., the city of Königsberg and the relevant graph are related to each other in virtue of the physical structure of the city). Liggins offers a general analysis of how "quantitative relations" may obtain. His preferred solution is that the obtaining of these relations is explained by the objects' possession of nominalistic properties, so that platonists should also give nominalistic explanations of the obtaining of these quantitative relations. Liggins considers a class of easy road responses to indispensability arguments according to which the main role of the appeal to mathematical 
objects is the enhancement of expressive power (rather than explanatory power). He then advances a modification of Field's hard road response, which he dubs "the fast lane": nominalists taking the fast lane will appeal, in explanation of physical phenomena, to those nominalistic grounds that platonists need to assume when offering their explanations. Liggings also discusses several advantages of the fast lane strategy by showing how it avoids some limitations of Field's program, and defends it from various objections: most importantly, his strategy offers a form of abstract expressivism that is immune to Colyvan's "content challenge" (the challenge to nominalists that they should explain what is conveyed by the use of platonistic theories). Even though Liggins remains open as to whether the fast lane strategy can be successful, he insists that the consideration of grounding relations in the assessment of explanation-based indispensability arguments may further our understanding of the platonism versus nominalism debate.

Matteo Plebani, in "Nominalistic content, grounding, and covering generalizations," discusses Liggins's fast lane strategy, in particular with respect to its compatibility with easy road strategies for nominalism. Plebani first explores the extent to which easy road nominalists may endorse Liggins's strategy. Plebani conjectures that (hermeneutic) fictionalists willing to follow Liggins's fast lane may define the concrete content of mathematical statements in terms of that in virtue of which their full, literal content obtains, and notices that the conjecture seems plausible when simple cases are considered. He also defends the easy road strategy against one possible misguided worry, based on the fact that expressing the concrete content of a mathematical statement may itself indispensably require mathematical language. Plebani then advances two reasons for concern. One arises for the fast lane strategy once one realizes that the nominalistic ground of some allegedly mathematical explanation can be described at different levels of generality. Another arises for easy road nominalists endorsing Liggins's strategy: if they do endorse it, the conjectured definition of concrete content may have to be abandoned, since what grounds the full content of a mathematical statement may turn out not to be what is conveyed by an assertion of that statement. Finally, Plebani reminds us that some explanations (e.g. in the bridges of Königsberg's example) need not only appeal to some nominalistic fact, but also to some covering generalizations thereof: easy road nominalists have tools for providing these, but they may not involve an appeal to grounds of the sort Liggins proposes.

\section{References}

Azzouni, J. (2004). Deflating existential consequence: A case for nominalism. New York: Oxford University Press.

Baker, A. (2005). Are there genuine mathematical explanations of physical phenomena? Mind, 114, 223238.

Baker, A. (2009). Mathematical explanation in science. The British Journal for the Philosophy of Science, 60, 611-633.

Baker, A. (2012). Science driven mathematical explanation. Mind, 121(482), 243-267.

Baker, A., \& Colyvan, M. (2011). Indexing and mathematical explanation. Philosophia Mathematica, 19(3), 323-334.

Bangu, S. (2008). Inference to the best explanation and mathematical realism. Synthese, 160(1), 13-20.

Bangu, S. (2013). Indispensability and explanation. The British Journal for the Philosophy of Science, 64(2), 255-277. 
Batterman, R. (2010). On the explanatory role of mathematics in empirical science. British Journal for the Philosophy of Science, 61(1), 1-25.

Benacerraf, P. (1973). Mathematical truth. Journal of Philosophy, 70, 661-680.

Bueno, O., \& Colyvan, M. (2011). An inferential conception of the application of mathematics. Noûs, 45, 345-374.

Bueno, O., \& French, S. (2012). Can mathematics explain physical phenomena? British Journal for the Philosophy of Science, 63(1), 85-113.

Cartwright, N. (1983). How the laws of physics lie. New York: Oxford University Press.

Chihara, C. (1991). Constructibility and mathematical existence. Oxford: Oxford University Press.

Colyvan, M. (2001). The indispensability of mathematics. Oxford: Oxford University Press.

Colyvan, M. (2002). Mathematics and aesthetic considerations in science. Mind, 111(441), 69-74.

Colyvan, M. (2010). There is no easy road to nominalism. Mind, 119, 285-306.

Colyvan, M. (2012). Road work ahead: Heavy machinery on the easy road. Mind, 121, 1031-1046.

Daly, C., \& Langford, S. (2009). Mathematical explanation and indispensability arguments. The Philosophical Quarterly, 59(237), 641-658.

Field, H. (1980). Science without numbers. A defence of nominalism. Princeton, NJ: Princeton University Press.

Field, H. (1989). Realism, mathematics and modality. Oxford: Basil Blackwell.

van Fraassen, B. (1980). The scientific image. Oxford: Oxford University Press.

Frege, G. (1884). Die Grundlagen der Arithmetik. Eine logisch-mathematische Untersuchung über den Begriff der Zahl. Breslau: Koebner.

Frege, G. (1893-1903). Grundgesetze der Arithmetik, begriffsschriftlich abgeleitet. Pohle, Jena.

Friend, M., \& Molinini, D. (2015). Using mathematics to explain a scientific theory. Philosophia Mathematica. doi:10.1093/philmat/nkv022.

Garavaso, P. (2005). On Frege's alleged indispensability argument. Philosophia Mathematica, 13, 160-173.

Giere, R. (1988). Explaining science: A cognitive approach. Chicago: The University of Chicago Press.

Gödel, K., (1947). What is cantor's continuum problem? The American Mathematical Monthly, 54, pp. 515-525; reprinted in Kurt Gödel: Collected works, Vol. II: Publications 1938-1974, S. Feferman, (Ed.-in-chief), Oxford University Press, Oxford, 1990, pp. 176-187.

Gödel, K. (1964). What is cantor's continuum problem?, revised and expanded version of Gödel 1947, in Philosophy of mathematics - Selected readings, P. Benacerraf \& H. Putnam, (Eds.), 1964, pp. 258-276 (1st ed.) and 1983, pp. 470-485 (2nd ed.); also in Kurt Gödel: Collected Works, Vol. II: Publications 1938-1974, S. Feferman, (Ed.-in-chief), Oxford University Press, Oxford, 1990 pp. 254-270.

Hacking, I. (1983). Representing and intervening. Cambridge: Cambridge University Press.

Hafner, J., \& Mancosu, P. (2008). Beyond unification. In P. Mancosu (Ed.), The philosophy of mathematical practice, pp. 151-179.

Hale, B., \& Wright, C. (2001). The reason's proper study. Oxford: Oxford University Press.

Hellman, G. (1989). Mathematics without Numbers. Oxford: Oxford University Press.

Leng, M. (2005). Mathematical explanation. In C. Cellucci \& D. Gillies (Eds.), Mathematical reasoning, heuristics and the development of mathematics (pp. 167-189). London: King's College Publications.

Lipton, P. (2004). Inference to the best explanation (2nd ed.). London: Routledge International Library of Philosophy.

Lyon, A. (2011). Mathematical explanations of empirical facts, and mathematical realism. Australasian Journal of Philosophy, 90(3), 559-578.

Lyon, A., \& Colyvan, M. (2008). The explanatory power of phase spaces. Philosophia Mathematica, 16(2), 227-243.

Maddy, P. (1990). Physicalistic platonism. In A. Irvine (Ed.), Physicalism in mathematics (pp. 259-289). Dordrecht: Kluwer Academic Publishers.

Maddy, P. (1992). Indispensability and practice. The Journal of Philosophy, 89(6), 275-289.

Mancosu, P. (2008). Mathematical explanation: Why it matters. In P. Mancosu (Ed.), The philosophy of mathematical practice (pp. 134-149). Oxford: Oxford University Press.

Mancosu, P. (2011). Explanation in mathematics. In E. N. Zalta (Ed.), The Stanford encyclopedia of philosophy (summer 2011 ed.). Stanford: Stanford University.

Mancosu, P., \& Pincock, C. (2012). Mathematical explanation. Oxford Bibliographies in Philosophy. doi:10. 1093/obo/9780195396577-0029.

Melia, J. (2000). Weaseling away the indispensability argument. Mind, 109(435), 455-479.

Melia, J. (2002). Response to Colyvan. Mind, 111, 75-79. 
Mill, J. S. (1843). A system of logic, ratiocinative and inductive. London: Longmans.

Molinini, D. (2011). Towards a pluralist approach to mathematical explanation of physical phenomena. Lille: ANRT.

Molinini, D. (2014). Deductive nomological model and mathematics: Making dissatisfaction more satisfactory. Theoria-An International Journal for Theory, History and Foundations of Science, 80, $223-242$.

Panza, M., \& Sereni, A. (2013). Plato's problem. An introduction to mathematical platonism. Basingstoke: Palgrave Macmillan.

Parsons, C., (1979-1980). Mathematical intuition. Proceedings of the Aristotelian Society, new series, 80, pp. $145-168$.

Pincock, C. (2004). A new perspective on the problem of applying mathematics. Philosophia Mathematica, 3(12), 135-161.

Pincock, C. (2007a). A role for mathematics in the physical sciences. Noûs, 41(2), 253-275.

Pincock, C. (2007b). Mathematical idealization. Philosophy of Science, 74, 957-967.

Pincock, C. (2012). Mathematics and scientific representation. Oxford: Oxford University Press.

Pincock, C. (2014). Abstract explanations in science. The British Journal for the Philosophy of Science. doi:10.1093/bjps/axu016.

Putnam, H. (1971). The philosophy of logic. New York: Harper and Row.

Quine, W. V. O. (1948). On what there Is. Review of Metaphysics, 2, pp. 21-38, reprinted in Quine 1953: ch. 1 .

Quine, W. V. O. (1951). Two dogmas of empiricism. Philosophical Review, 60, pp. 20-43, reprinted in Quine 1953: ch. 2.

Quine, W. V. O. (1953). From a logical point of view (2nd ed., 1961). New York: Harper \& Row.

Quine, W. V. O. (Ed.). (1966). The scope and language of science. In The ways of paradox and other essays, Columbia University Press, New York, 1966, chapter 22, 2nd revised edition, 1976.

Quine, W. V. O. (Ed.). (1969). Existence and quantification. L'Âge de la Science, 1, pp 151-64; also in Ontological relativity and other essays, Columbia University Press, New York and London, 1969, chapter 4.

Quine, W. V. O. (Ed.). (1981). Success and limits of mathematization. In Theories and things (pp. 148-155). Cambridge, MA: Harvard University Press. 1981.

Resnick, M. (1995). Scientific versus mathematical realism: The indispensability argument. Philosophia Mathematica, 3(2), 166-174.

Rizza, D. (2011). Magicicada, mathematical explanation and mathematical realism. Erkenntnis, 74, 101114.

Saatsi, J. (2011). The enhanced indispensability argument: Representational versus explanatory role of mathematics in science. The British Journal for the Philosophy of Science, 62, 143-154.

Salmon, W. (1984). Scientific explanation and the causal structure of the world. Princeton, NJ: Princeton University Press.

Sandborg, D. (1998). Mathematical explanation and the theory of why-questions. British Journal for the Philosophy of Science, 49, 603-624.

Sereni, A. (2015). Frege, indispensability, and the compatibilist heresy. Philosophia Mathematica, 23(1), 11-30.

Shapiro, S. (1983). Mathematics and reality. Philosophy of Science, 50, 523-548.

Shapiro, S. (1997). Philosophy of mathematics: Structure and ontology. Oxford: Oxford University Press.

Sober, E. (1993). Mathematics and indispensability. Philosophical Review, 102, 35-58.

Steiner, M. (1978a). Mathematical explanation. Philosophical Studies, 34, 135-151.

Steiner, M. (1978b). Mathematics, explanation and scientific knowledge. Noûs, 12, 17-28.

Steiner, M. (2005). The myth of the seven. In M. E. Kalderon (Ed.), Fictionalism in metaphysics (pp. 88-115). Oxford: Oxford University Press.

Tallant, J. (2013). Optimus prime: Paraphrasing prime number talk. Synthese, 190, 2065-2083.

Yablo, S. (2001). Go figure: A path through fictionalism. Midwest Studies in Philosophy, XXV, pp. 72-102.

Yablo, S. (2005). The myth of the seven. In M. E. Kalderon (Ed.), Fictionalism in metaphysics (pp. 88-115). Oxford: Oxford University Press. 